\title{
Three new genera and five new species of the tribe Meconematini (Orthoptera: Tettigoniidae: Meconematinae) from Southwestern China
}

\author{
Yan-Lin $\mathrm{CHANG}^{\circledR 1}$, Tao WANG ${ }^{\circledR 2}$ \& Fu-Ming $\mathrm{SHI}^{\circledR 3}$ 3,* $^{*}$ \\ ${ }_{1,2,3}$ College of Life Science, Institute of Life Science and Green Development, Hebei University, \\ Baoding 071002, P.R. China. \\ *Corresponding author: shif_m@126.com \\ ${ }^{1}$ Email: changylin@126.com \\ 2Email:w970528354@163.com \\ ${ }^{1}$ urn:1sid:zoobank.org:author:325C4E06-ECD0-4B03-A1ED-A3CCA7E050C7 \\ ${ }^{2}$ urn:1sid:zoobank.org:author:3B0E6688-415B-4C68-8A07-69846E17C561 \\ ${ }^{3}$ urn:1sid:zoobank.org:author:9E53A7F0-4FEB-4AED-8E3C-BD1AB497154D
}

\begin{abstract}
This paper deals with the brachypterous Meconematini, including three new genera, Acosmetides gen. nov., Neocyrtopsides gen. nov. and Macrocosmetura gen. nov. Five new species are described: Acosmetides peltates gen. et sp. nov., Acosmetides dilobosa gen. et sp. nov., Acosmetides platycerca gen. et sp. nov., Neocyrtopsides bispina gen. et sp. nov. and Macrocosmetura truncata gen. et sp. nov. Two new combinations are proposed: Acosmetides trigentis (Wang, Bian \& Shi, 2016) gen. et comb. nov. and Neocyrtopsides platycata (Shi \& Zheng, 1994) gen. et comb. nov.
\end{abstract}

Keywords. Brachypterous Meconematini, new genera, new species, new combinations, China.

Chang Y.L., Wang T. \& Shi F.M. 2021. New taxa of the tribe Meconematini (Orthoptera: Tettigoniidae: Meconematinae) from Southwestern China. European Journal of Taxonomy 751: 140-158.

https://doi.org/10.5852/ejt.2021.751.1385

\section{Introduction}

The tribe Meconematini Burmeister, 1838 is rich and diverse at the genus and species level in Southeast Asia (Gorochov 1993, 1998, 2014, 2015; Sänger \& Helfert 1996, 2000, 2004; Ingrisch \& Shishodia 1998, 2000; Tan et al. 2017; Tan \& Wahab 2018) and East Asia (Xia \& Liu 1992; Gorochov 2002, 2005, 2008, 2011, 2012; Kano et al. 1999; Liu 2000; Gorochov et al. 2005; Wang H.J. et al. 2013; Wang H.Q. et al. 2013, 2014, 2015a, 2015b), where some new genera and many new species are still being discovered (Gorochov 2019; Chen et al. 2019; Cui et al. 2019, 2020; Wang T. et al. 2019a, 2019b, 2020a, 2020b). Some genera and species are endemic to China (Liu \& Zhou 2007; Bian et al. 2012a, 2012b, 2013, 2014, 2017; Shi \& Bian 2012, 2013; Wang H.Q. et al. 2012, 2015a; Shi et al. 2013), especially brachypterous groups, most of which occur in South, Southwest and Central China (Bian et al. 2012a, 2012b, 2013; Wang H.Q. et al. 2015b; Cui et al. 2019, 2020; Wang T. et al. 2019a, 2019b, 2020a, 2020b, 2020c). 


\title{
Material and methods
}

The brachypterous Meconematini groups are flightless and restricted to narrow distribution areas. The type localities of the species described in this paper are distributed in Yunnan, Guizhou, Guangxi, Sichuan and Hunan, China.

The material was collected by us and the graduate students during the last two decades, and the type specimens of the new species are preserved in the Museum of Hebei University (HBU).

Morphological images were acquired using a Leica M205A digital imaging system. The following conventions were adopted for the specimen measurements: body = distance from apex of fastigium verticis to posterior margin of tenth abdominal tergite; pronotum $=$ distance from anterior to posterior margin of pronotum; hind femur = distance from base of hind femur to apex of genicular lobe; ovipositor = distance from subgenital plate base to apex of ovipositor.

\section{Results}

\author{
Order Orthoptera Latreille, 1810 \\ Suborder Ensifera Chopard, 1921 \\ Family Tettigoniidae Krauss, 1902 \\ Subfamily Meconematinae Burmeister, 1838 \\ Tribe Meconematini Burmeister, 1838 \\ Genus Acosmetides gen. nov. \\ urn:1sid:zoobank.org:act:BF6B036C-62A0-4D4B-8D46-902BCF95D387
}

\section{Type species}

Acosmetides peltates gen. et sp. nov.

\section{Diagnosis}

The new genus resembles the genus Acosmetura Liu, 2000, but differs from it in the following characters: male tenth abdominal tergite protruded backwards with posterior margin split or concave; subgenital plate with basal area broad, apical area narrow, with a median lobe.

\section{Etymology}

The name of the new genus is derived from the genus name Acosmetura and the Greek '-ides', meaning 'alike'. The Chinese name of the genus is 拟异饰尾虫属 (Ni Yi Shi Wei Zhong Shu).

\section{Generic characters}

Body small-sized, stout. Frons vertical, or sloping backwards. Fastigium verticis conical, apex obtuse, furrowed dorsally. Apical segment of maxillary palpus longer than subapical one. Male pronotum moderately extended backwards, shorter in female, lateral lobe longer than deep, posterior area tapering. Tegmina short, apices surpassing posterior margin of pronotum, or concealed beneath pronotum. Foretibial tympana open and oval on both sides. Genicular lobes of hind femur rounded, without spines. Male tenth abdominal tergite slightly elongated, posterior margin concave, or split; genitalia sclerotized, short; cercus medium long, usually dorsal surface of the middle area concave downwards, apex upcurved; subgenital plate with broad basal area, apical half narrow, only with a median lobe. Styli inserted on lateral margins of apical one third of subgenital plate. Ovipositor moderately upcurved. 


\section{Acosmetides peltates gen. et sp. nov. urn:lsid:zoobank.org:act:C687D6B4-CB1B-4E49-9471-37948C2C3815}

Fig. 1

\section{Diagnosis}

The new species is similar to its congeners in appearance, but differs from them in male genitalia, subgenital plate and tenth abdominal tergite.

\section{Etymology}

The name of the new species refers to the morphology of the male genitalia, the Greek 'peltate-' meaning 'shield-shaped'. The Chinese name of the species is 盾形拟异饰尾蚉 (Dun Xing Ni Yi Shi Wei Zhong).

\section{Material examined}

\section{Holotype}

CHINA • Ȯ; Yunnan, Weixin, Daxueshan; 20 Aug. 2012; Xun Bian leg.; HBU.

\section{Paratypes}

CHINA 1 $1 \lambda, 1$; same collection data as for holotype; HBU $\bullet 8 \lambda \hat{\partial}, 2$ q $O+$; same collection data

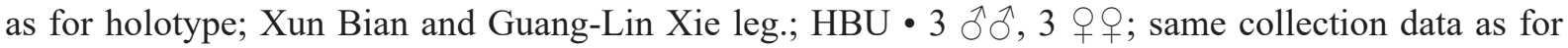
holotype; 19 Aug. 2012; Xun Bian and Guang-Lin Xie leg.; HBU • 1 ${ }^{\lambda}, 3$ q $ᄋ$; same collection data as for holotype; 21 Aug. 2012; Xun Bian leg.; HBU • 1 क; Yunnan, Daguan, Mugan; 27 Aug. 2012; Xun Bian and Guang-Lin Xie leg.; HBU • 1 क; Yunnan, Yiliang, Xiaocaoba; 29 Jul. 2006; Long-Guan Chen

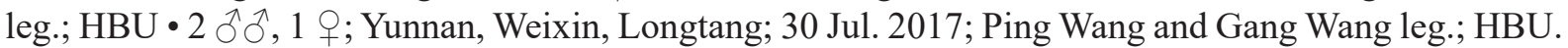

\section{Description}

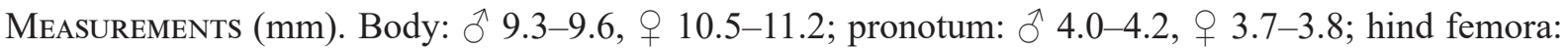
ふ 9.5-9.7, q 9.8-10.3; ovipositor: 6.0-6.5.

BoDy. Small and stout.

HEAD. Short; frons slightly sloping backwards. Fastigium verticis conical, with longitudinal sulcus on dorsum. Apical segment of maxillary palpus slightly longer than subapical one, apical area inflated, terminal truncated. Eyes globular, prominent.

THORAX. Pronotum protruded backwards, reaching posterior margin of first abdominal tergite, or anterior margin of second abdominal tergite; anterior margin roughly straight, posterior margin rounded; hind transverse sulcus distinct; lateral lobe longer than deep, posterior margin tapering; humeral sinus absent. Thoracic auditory spiracle exposed, small and oval.

TEGMEN. Tegmina short, most covered by pronotum, apices surpassing posterior margin of pronotum, obtusely rounded. Hind wings absent.

Legs. All femora unarmed on ventral surfaces. Fore coxa with a spine; fore tibia with 5 medium long symmetrically arranged spines on both sides of ventral surface, tibial tympana open and oval on both sides. Middle tibia with 4-5 spines on inner and outer margins of ventral surface. Hind femur with apices of knees obtuse; hind tibia with 22-24 spines on inner and outer margins of dorsal surface, bearing 2 pairs of ventral apical spurs and 1 pair of dorsal apical spurs.

MaLe ABdomen. Ninth abdominal tergite with lateral margin slightly broadened backwards. Tenth abdominal tergite narrow, posterior margin of middle area protruded backwards, apical area with median 


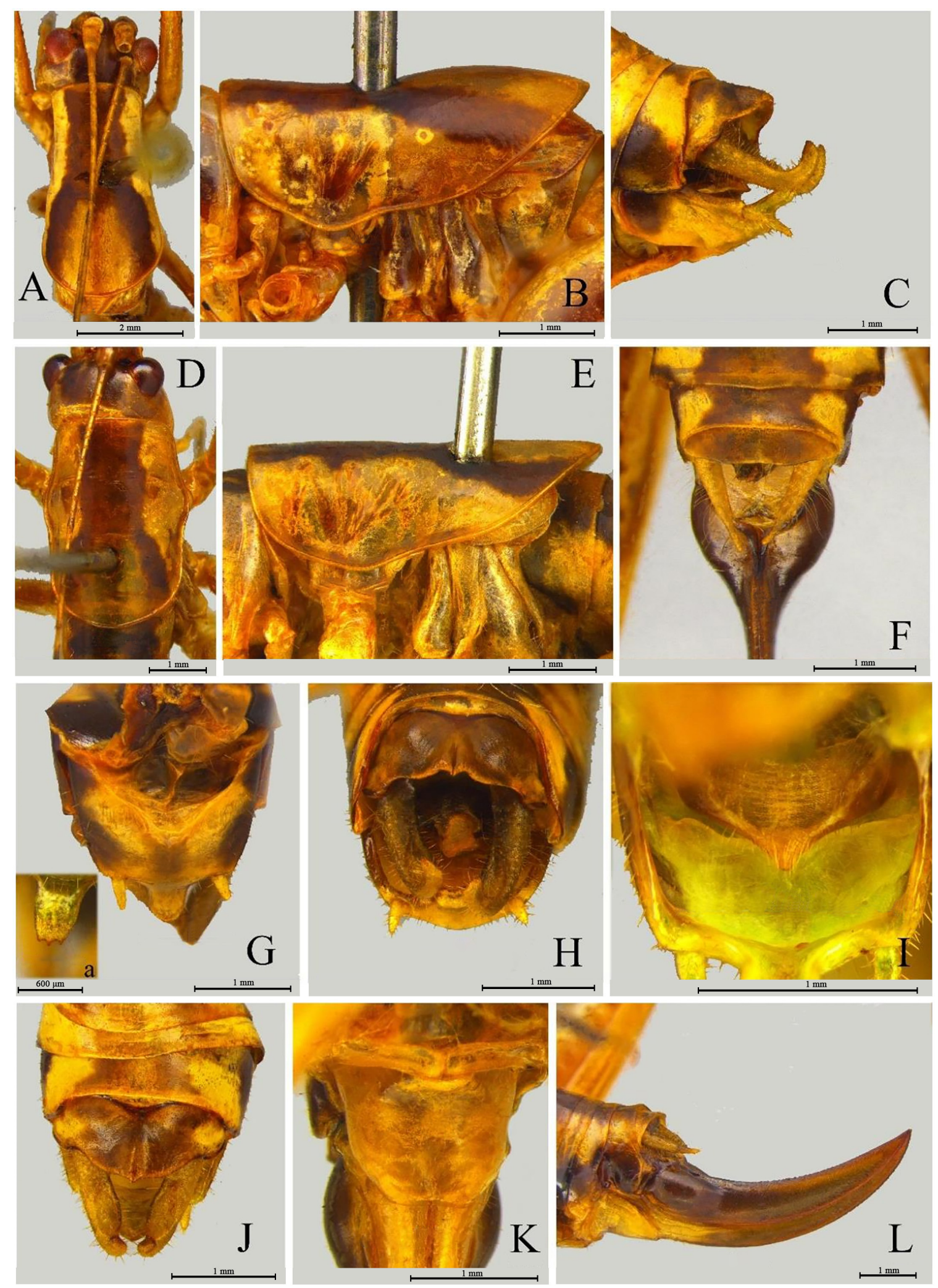

Fig. 1. Acosmetides peltates gen. et sp. nov. A-C, G-J. Holotype, §̊ (HBU). D-F, K-L. Paratype, $q$ (HBU). - A-B, D-E. Pronotum. A, D. Dorsal view. B, E. Lateral view. - C, F-L. Apex of abdomen. C. Lateral view. F, J. Dorsal view. H. Apico-dorsal view. I. Apical area of genitalia in ventral view. G, K. Subgenital plate in ventral view; a = apical area of subgenital plate. L. Ovipositor in lateral view. 
sulcus, which splits. Cercus with base cylindrical, middle area concave downwards, apex upcurved, twisted, inner edge ridge-shaped, apex indistinctly tooth-shaped. Genitalia sclerotized, shield-shaped, broad, terminal papillary. Subgenital plate with base broad, basal margin concave triangularly; apical half narrow, only with a median lobe, moderately upcurved, apex with small spine-shaped process on the middle. Styli short, conical, apices rounded, inserted on lateral margins near apical one third of subgenital plate.

Female. Pronotum shorter than in male. Tegmina short, most covered by pronotum. Cerci long conical, apices subacute. Subgenital plate with base broad, ventral surface of which with a colliculus process; lateral margins tapering, posterior margin slightly concave. Ovipositor moderately upcurved with finely serrated dorsal and ventral margins along entire length, apex acute.

Coloration. Body yellowish brown, with admixed brown spots, some area light green when alive. Head with dorsum brown, eyes brown. Disc of pronotum with longitudinal brown stripe, which bifurcates in metazona, other area of which is light. All tarsi light brown, spines on all tibiae brown. Outer surface of hind femur with some parallel light brown spots, hind knees brown, apex of hind tibia brown. Lateral surface of abdomen brown.

\section{Remarks}

In some populations, lateral lobes of pronotum with ventral edge brown. The middle lobe of male subgenital plate with a pair of indistinct small spines on lateral sides of subapex.

\section{Distribution}

China (Guizhou, Yunnan).

Acosmetides dilobosa gen. et sp. nov. urn:lsid:zoobank.org:act:61431199-1286-4017-BFD8-DF2BC6C2727B

Fig. 2

\section{Diagnosis}

The new species resembles Acosmetides peltates gen. et sp. nov., but differs from it in male tenth abdominal tergite and genitalia.

\section{Etymology}

The name of the new species refers to the morphology of the tenth abdominal tergite in males, the posterior part of which has a pair of lateral lobes. Greek 'di-' means with 'two' and 'lobos' means 'lobe'. The Chinese name of the species is 双叶拟异饰尾蚉 (Shuang Ye Ni Yi Shi Wei Zhong).

\section{Material examined}

\section{Holotype}

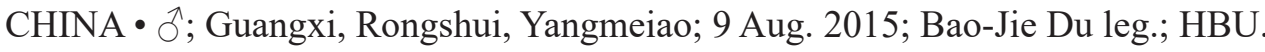

\section{Description}

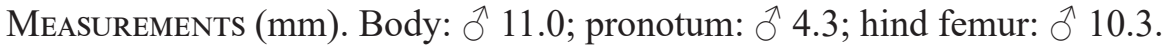

BoDy. Small.

HEAD. Fastigium verticis conical, apex obtuse, furrowed dorsally. Apical segment of maxillary palpus longer than subapical one, apical area inflated, terminal truncate. Eyes spherical, protruded forwards. 
Thorax. Pronotum slightly elongated, reaching posterior margin of first abdominal tergite, anterior margin roughly straight, posterior margin rounded; hind transverse sulcus distinct; lateral lobe longer than high, with tapering posterior area, humeral sinus absent. Thoracic auditory spiracle exposed, small, pear-shaped.

Tegmen. Tegmina short, surpassing posterior margin of pronotum, apices rounded. Hind wings absent.

Legs. All femora unarmed on ventral surfaces. Fore coxa with a spine; fore tibia with 5 medium long spines on inner and outer sides of ventral surface, tibial tympana open and oval on both sides. Middle tibia with 5-6 spines on inner and outer margins of ventral surface. Hind tibia with 24-27 spines on each side of dorsal surface, bearing 2 pairs of ventral apical spurs and 1 pair of dorsal apical spurs.

MALE ABDOMEN. Ninth abdominal tergite with lateral areas slightly expanded backwards. Tenth abdominal tergite extended backwards, with a U-shaped notch at the middle of posterior margin, divided into two lateral lobes, apices subacute. Genitalia sclerotized, base broad, other area very narrow, apex bifurcated. Cercus with base cylindrical, dorsal surface of middle area concave downwards, apical area upcurved, slightly twisted, inner margin ridge-shaped, apex rounded. Subgenital plate with base broad, terminal half conical, apex rounded. Styli long conical, apices obtuse, inserted on lateral margins near middle area of subgenital plate.

FEMALE. Unknown.

Coloration. Body yellowish brown. Dorsum of head brown, eyes brown, scapus and pedicel of antenna brown. Disc of pronotum with broad longitudinal brown stripe in prozona, splitting into two branches

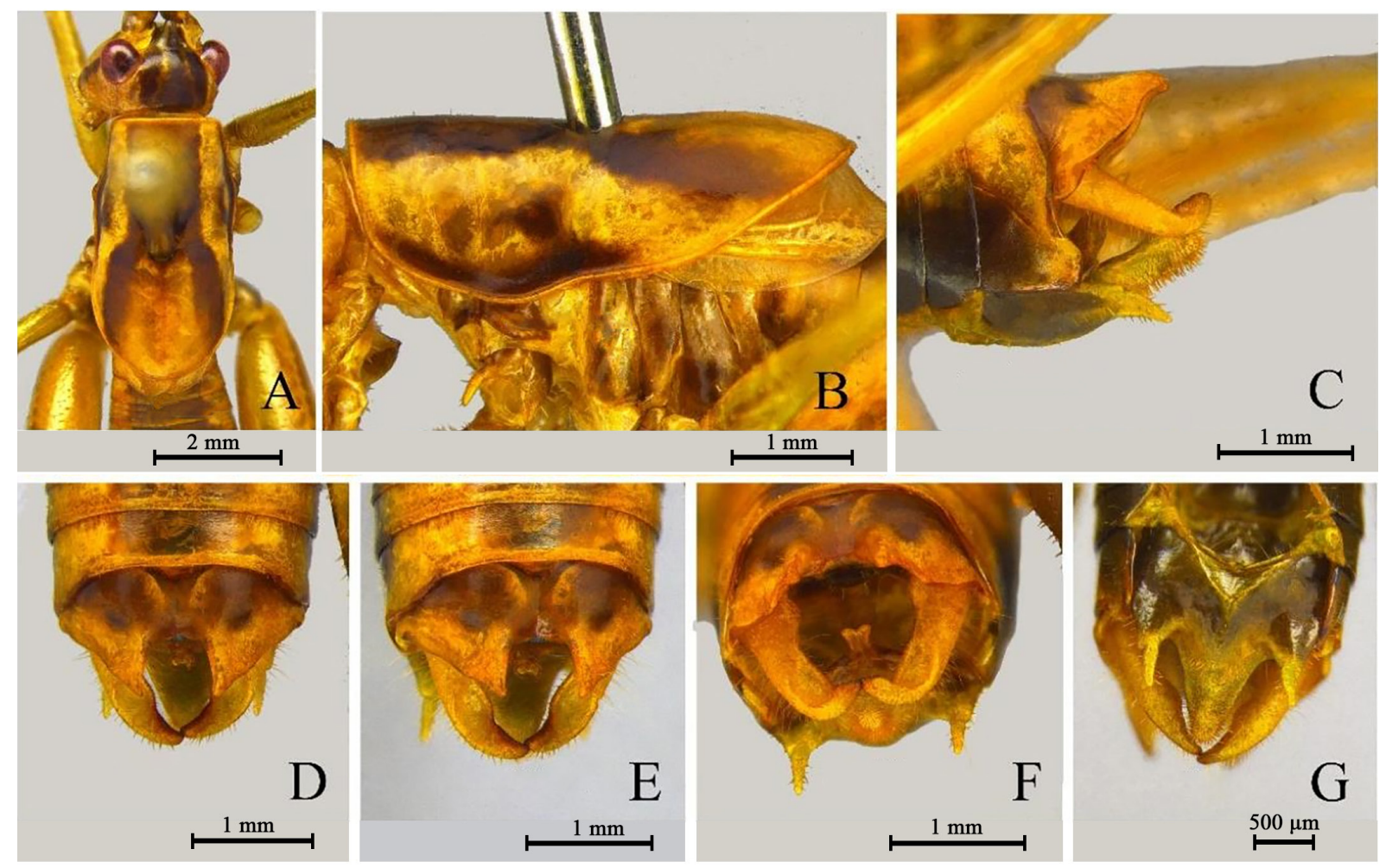

Fig. 2. Acosmetides dilobosa gen. et sp. nov., holotype, ð̋ (HBU). - A-B. Pronotum. A. Dorsal view. B. Lateral view. - C-G. Apex of abdomen. C. Lateral view. D-E. Dorsal view. F. Apico-dorsal view. G. Ventral view. 
in metazona, most of which is light; ventral edge of lateral lobe with narrow brown stripe. Outer surface of hind femur with indistinctly light brown spots; knee area of hind femur brown, spines on all tibiae brown. Dorsum of abdomen brown, ventro-lateral surface of which dark brown.

\section{Distribution}

China (Guangxi).

Acosmetides platycerca gen. et sp. nov.

urn:lsid:zoobank.org:act:5C6A4228-2300-44D9-BCD7-22AA72A87175

Fig. 3

\section{Diagnosis}

The new species is similar to its congeners in appearance, but differs from them in male cerci and genitalia.

\section{Etymology}

The name of the new species is derived from the Latin 'platy-', meaning 'broadened', and 'cerc-', meaning 'cercus'. The Chinese name of the species is 宽尾拟异饰尾虫 (Kuang Wei Ni Yi Shi Wei Zhong).

\section{Material examined}

\section{Holotype}

CHINA • O'; Yunnan, Weixin, Daxueshan; 19 Aug. 2013; Xun Bian and Guang-Lin Xie leg.; HBU.

\section{Paratype}

CHINA・1 3 ; same collection data as for holotype; 21 Aug. 2013; Xun Bian leg.; HBU.

\section{Additional material}

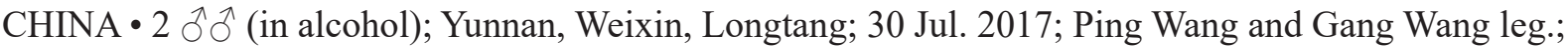
HBU.

\section{Description}

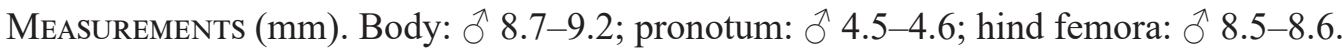

BoDy. Small and stout.

HEAD. Frons slightly sloping backwards. Fastigium verticis conical, apex rounded with longitudinal sulcus on dorsum. Apical segment of maxillary palpus longer than subapical one, apical area inflated, apex truncate. Eyes globular, protruded forwards.

THORAX. Pronotum elongated backwards, reaching posterior margin of first abdominal tergite; posterior transverse sulcus distinct; anterior margin roughly straight, posterior margin obtusely rounded; lateral lobes longer than deep, posterior margin tapering, humeral sinus absent. Thoracic auditory spiracle exposed, small, pear-shaped.

TEGMEN. Tegmina short, slightly surpassing posterior margin of pronotum. Hind wings absent.

LEGS. All femora unarmed on ventral surfaces. Fore coxa with spine; fore tibia with 5 medium long spines on each side of ventral surface, tibial tympana open and ovoid on both sides. Hind femur with genicular lobes rounded; hind tibia with 24-26 spines on each side of dorsal surface, bearing 2 pairs of ventral apical spurs and 1 pair of dorsal apical spurs. 
CHANG Y.L. et al., New taxa of Meconematini

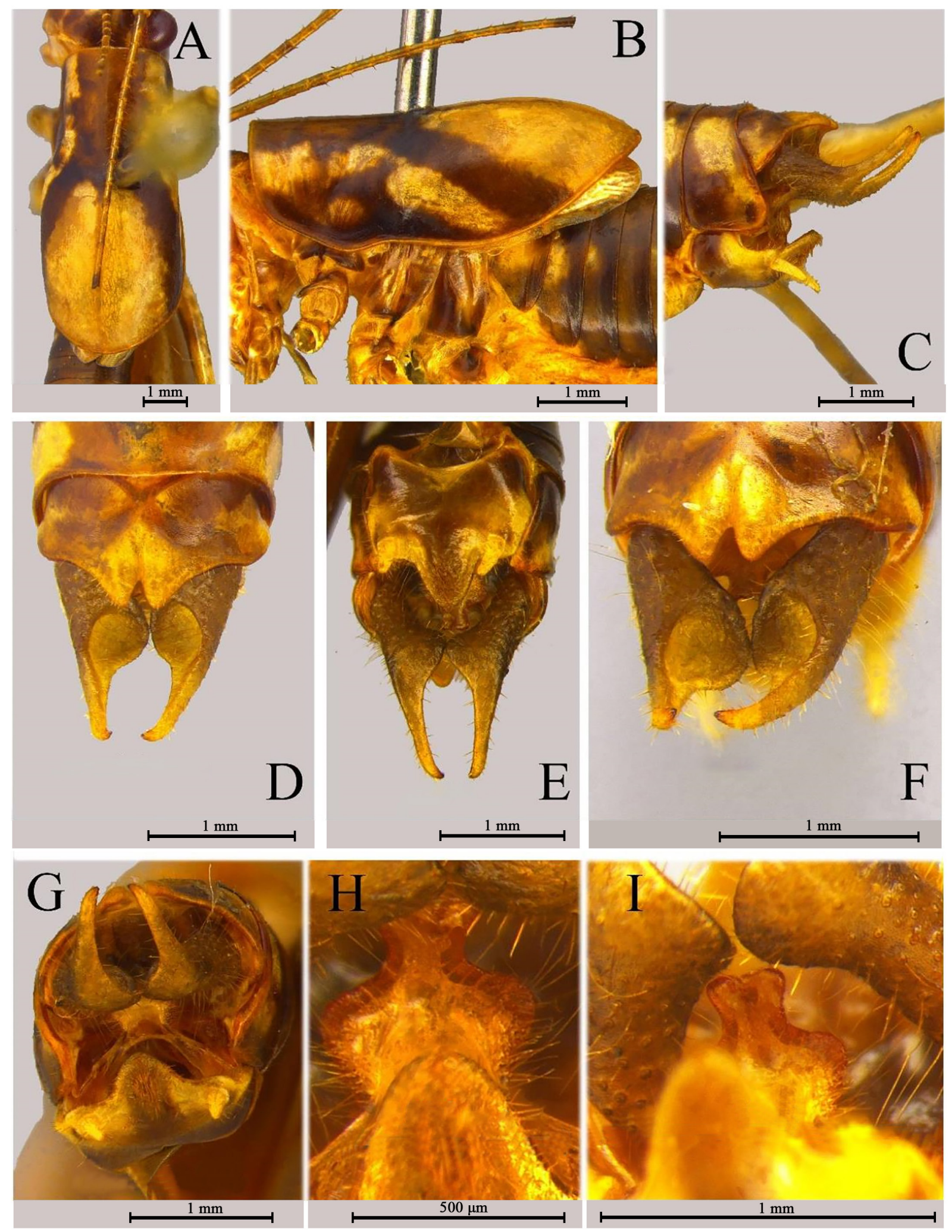

Fig. 3. Acosmetides platycerca gen. et sp. nov., holotype, $\widehat{\jmath}$ (HBU). - A-B. Pronotum A. Dorsal view. B. Lateral view. - C-G. Apex of abdomen. C. Lateral view. D. Dorsal view. E. Ventral view. F. Dorsoapical view. G. Apical view. - H-I. Genitalia in ventral view. H. Basal area. I. Apical area. 
MaLe ABdomen. Ninth abdominal tergite with lateral surface slightly broadened backwards. Tenth abdominal tergite with base half broad, apical half tapering, with a triangular notch on the middle of posterior margin, divided into two lateral lobes with apices rounded. Cercus with base thin, middle area widened, with a semiglobular concavity; apical area thin, apices incurved. Genitalia sclerotized, base area with circular lateral process on each side; middle area broadened, lamellate, near apex shrunk, subapex slightly broadened, apex roughtly truncate. Subgenital plate with basal area rectangular, apical area triangular, apex rounded. Styli long with apices rounded, inserted on lateral margins near apical one third.

Female. Unknown.

Coloration. Body light yellowish brown, with admixed brown spots. Dorsum of head brown, frons with 1 pair of longitudinal brown stripes, scapus and pedicel of antenna brown. Disc of pronotum with longitudinal brown stripe at prozona, which bifurcates into two branches at metazona, most of which is light; lateral lobe light, with brown stripe on ventral edge. All spines on tibiae brown. Abdomen brown, tenth abdominal tergite with apex light. Cerci brown, apices blackish brown. Styli light.

\section{Distribution}

China (Yunnan).

Acosmetides trigentis (Wang, Bian \& Shi, 2016) gen. et comb. nov.

Acosmetura trigentis Wang, Bian \& Shi, 2016: 390.

\section{Remarks}

The original description of the species is exact and the figure is clear (Wang P. et al. 2016). Based on the male tenth abdominal tergite with a notch in the middle of the posterior margin and the middle lobe of the subgenital plate distinct, the species should belong to the genus Acosmetides gen. nov.

\section{Note}

The Chinese name of the species is 三突拟异饰尾虫 (San Tu Ni Yi Shi Wei Zhong).

\section{Distribution}

China (Hubei).

Genus Neocyrtopsides gen. nov.

urn:1sid:zoobank.org:act:E3F4E5EA-C956-49E9-A282-DC69968F2B4B

\section{Type species}

Neocyrtopsides bispina gen. et sp. nov.

\section{Diagnosis}

The new genus is similar to Neocyrtopsis Liu \& Zhang, 2007, but differs from it in the following characters: male tenth abdominal tergite extended backwards, divided into two lateral lobes with apices obtuse, which fuse with epiproct, with rectangular notch between lobes; genitalia sclerotized, long, exposed. Male subgenital plate with middle lobe; styli inserted on lateral margins near middle of subgenital plate.

\section{Etymology}

The name of the new genus is derived from the genus name Neocyrtopsis, and the Greek '-ides', meaning 'alike'. The Chinese name of the genus is 拟新刺膝蚉属 (Ni Xin Ci Xi Zhong Shu). 


\section{Generic characters}

Body small, robust. Frons slightly sloping backwards, fastigium verticis conical, terminal obtuse, furrowed dorsally. Apical segment of maxillary palpus longer than subapical one, apical area inflated, apex truncate. Eyes globular, protruded forwards. Pronotum short, posterior area of lateral lobes tapering. Tibial tympana open and ovoid on both sides; genicular lobes of hind femora with apices rounded. Male tenth abdominal tergite elongated backwards and curved down, divided into 1 pair of lateral lobes with apices rounded; posterior margin fused with epiproct, after which with a rectangular notch; genitalia sclerotized, long, exposed; subgenital plate with basal area broad, terminal narrow, only with a middle lobe; styli inserted on lateral margins near the middle of subgenital plate.

Neocyrtopsides bispina gen. et sp. nov. urn:1sid:zoobank.org:act:AAC4C38A-F342-4144-BE5C-8435E2F0D5C2

Fig. 4

\section{Diagnosis}

The new species is similar to Neocyrtopsides platycata (Shi \& Zheng, 1994) gen. et comb. nov., but differs from it in male genitalia and subgenital plate.

\section{Etymology}

The name of the new species refers to the morphology of the male genitalia, the Latin ' $b i$-' meaning 'a pair' and 'spin-' meaning 'spine-shaped'. The Chinese name of the species is 双刺拟新刺膝虫 (Shuang Ci Ni Xin Ci Xi Zhong).

\section{Material examined}

Holotype

CHINA $-{ }^{7}$; Guizhou, Leishan, Leigongshan, Lianhuaping; 15 Sep. 2005; Fu-Ming Shi leg.; HBU.

\section{Paratype}

CHINA • 1 क ; same collection data as for holotype; HBU.

\section{Description}

MeAsurements (mm). Body: đo 10.0, o 10.7; pronotum: đ̂ 3.6, q 3.4; hind femora: ô 8.5, q 9.6; ovipositor: 6.5 .

BoDy. Small and stout.

HEAD. Frons slightly sloping backwards, fastigium verticis conical, apex rounded, furrowed dorsally. Apical segment of maxillary palpus longer than subapical one, apical area inflated, apex truncate. Eyes globular, protruded forwards.

THORAX. Pronotum short, anterior margin roughly straight, posterior margin rounded; lateral lobes longer than deep, with posterior area tapering; humeral sinus absent. Thoracic auditory spiracle exposed, small, elliptic.

TEGMEN. Tegmina short, mostly concealed beneath pronotum, only narrow edge visible. Hind wings absent.

LEGS. All femora unarmed on ventral surfaces. Fore coxa with spine; fore tibia with 5 spines on inner side and 4 spines on outer side of ventral surface; tibial tympana open and oval on both sides. Middle tibia 
with 4 short spines on each side of ventral surface. Hind tibia with 15-17 spines on each side of dorsal surface, bearing 2 pairs of ventral apical spurs and 1 pair of dorsal apical spurs.

MALE ABDOMEN. Ninth abdominal tergite slightly protruded backwards. Tenth abdominal tergite extended backwards, posterior area divided into 2 lateral lobes, apices broadened, posterior area fused with epiproct, after which is a rectangular concavity. Cercus cylindrical, lightly incurved, base slightly stout, apex tooth-
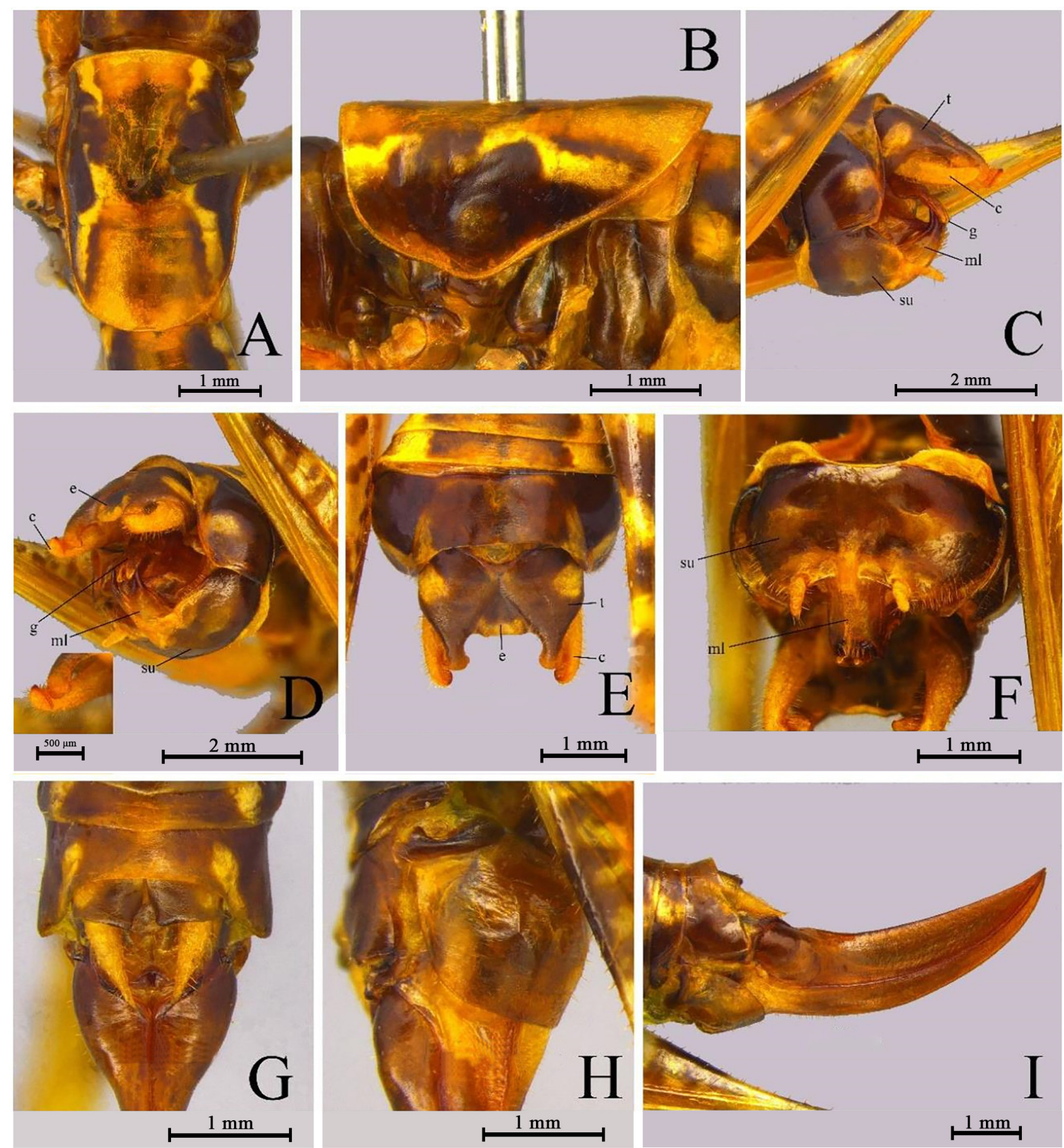

Fig. 4. Neocyrtopsides bispina gen. et sp. nov. A-F. Holotype, ô (HBU); G-I. Paratype, $q$ (HBU). A-B. Pronotum. A. Dorsal view. B. Lateral view. - C-E, G. Apex of abdomen. C. Lateral. D. Apico-lateral view. E, G. Dorsal view. - F, H. Subgenital plate. F. Ventral view. H. Ventro-lateral view. - I. Ovipositor in lateral view. Abbreviations: $\mathrm{c}=$ cercus; $\mathrm{e}=$ epiproct; $\mathrm{g}=$ genitalia; $\mathrm{ml}=$ middle lobe of subgenital plate; $\mathrm{su}=$ subgenital plate; $\mathrm{t}=$ tenth abdominal tergite. 
shaped. Genitalia sclerotized, dorsal branch narrow, near middle leaf-shaped expanded, lateral margins of apical half parallel, apex bispinose; ventral branch stout with apex thin (Fig. 4D). Subgenital plate with basal half broad, apical half narrow, lateral margins parallel, apex with a pair of spine-shaped processes, moderately upcurved. Styli long, inserted near base of middle lobe.

Female. Body thinner; tegmina short, anterior edges exposed. Ninth abdominal tergite with lateral areas expanded backwards, tenth abdominal tergite narrow, its middle split at posterior margin. Cerci conical, apices acute. Ovipositor moderately upcurved, base stout, terminal acute, dorsal and ventral margins smooth. Subgenital plate bowl-shaped, posterior margin roughly truncate.

Coloration. Body yellowish brown, with admixed brown spots. Dorsum of head brown. Pronotum with 1 pair of small brown spots on metazona, lateral lobes blackish brown. Ninth to tenth abdominal tergites dark brown. Cercus brown, apical area of subgenital plate and genitalia dark brown. Spines on all tibiae brown.

\section{Distribution}

China (Guizhou).

Neocyrtopsides platycata (Shi \& Zheng, 1994) gen. et comb. nov.

Phlugiolopsis platycata Shi \& Zheng, 1994: 44, 46 (English).

Acosmetura platycata - Liu et al. 2008: 764.

Neocyrtopsis (Paraneocyrtopsis) platycata - Wang H.J. et al. 2013: 182.

\section{Remarks}

The species was described by Shi \& Zheng (1994) on the basis of a single specimen (holotype) collected in Emeishan (Sichuan). Later, in 2011, we collected many specimens of the species from the type locality. Wang H.J. et al. (2013) determined the species should be placed in the genus Neocyrtopsis Liu \& Zhang, 2007 because of the morphology of the male tenth abdominal tergite and genitalia. However, after the species Neocyrtopsides bispina gen. et sp. nov. was discovered, it should be placed in the new genus because they differ from the genus Neocyrtopsis in the male epiproct, the tenth abdominal tergite, the genitalia and the subgenital plate morphology. The species was sufficiently described (see Wang H.J. et al. 2013).

\section{Distribution}

China (Sichuan).

\section{Note}

The Chinese name of the species is 宽板拟新刺膝蚉 (Kuang Ban Ni Xin Ci Xi Zhong).

Genus Macrocosmetura gen. nov.

urn:1sid:zoobank.org:act:BD653BDD-C0CC-495F-A4E1-718935D49C86

\section{Type species}

Macrocosmetura truncata gen. et sp. nov.

\section{Diagnosis}

The new genus resembles the genus Acosmetides gen. nov., but differs from it in the following characters: male and female ninth abdominal tergite markedly elongated ventrally, and tenth abdominal tergite extended backwards in both sexes with a concavity in the middle of the posterior margin. 


\section{Etymology}

The name of the new genus is derived from the Greek 'macr-', meaning 'large' or 'long', and the genus name Cosmetura. The Chinese name of the genus is 大饰尾蚉属 (Da Shi Wei Zhong Shu).

\section{Generic characters}

Body small, robust, comparatively large for the related genera. Fastigium verticis conical, apex rounded, furrowed dorsally. Eyes globular. Apical segment of maxillary palpus longer than subapical one, apical area inflated, apex truncate. Pronotum elongated backwards, posterior area of lateral lobe tapering. Ninth abdominal tergite with lateral surfaces protruding ventrally, apices finger-shaped; tenth abdominal tergite expanded backwards. Male genitalia sclerotized; subgenital plate with basal half broad, apical half with middle lobe and short paired lateral lobes.

Macrocosmetura truncata gen. et sp. nov. urn:lsid:zoobank.org:act:8752299A-3372-4DF9-AB26-D7341AF183E2

Fig. 5

\section{Diagnosis}

Male tenth abdominal tergite observably extended backwards and genitalia sclerotized, posterior area broad, apex truncate.

\section{Etymology}

The name of the new species refers to the morphology of the male genitalia, the word 'truncata' from the English 'truncate'. The Chinese name of the species is 截形大饰尾虫 (Jie Xing Da Shi Wei Zhong).

\section{Material examined}

Holotype

CHINA • \َ; Guizhou, Suiyang, Chachang; 15 Aug. 2010; Le-Hong Zhao leg.; HBU.

\section{Paratypes}

CHINA • 1 q; same collection data as for holotype; HBU • 1 \%; Guizhou, Suiyang, Rangshui; 13 Aug. 2010; Le-Hong Zhao leg.; HBU.

\section{Description}

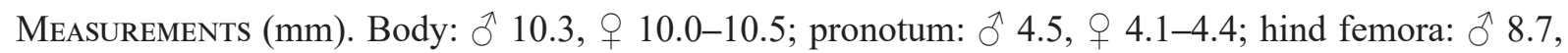
ㅇ 9.8-10.5; ovipositor: 6.2-6.3.

BoDy. Small and stout.

HEAD. Fastigium verticis conical, apex rounded, with median sulcus on dorsum. Eyes oval, protruded forwards. Apical segment of maxillary palpus longer than subapical one, apical area inflated, apex truncate.

THORAX. Pronotum longer, posterior margin reaching anterior margin of third abdominal tergite; lateral lobe longer than deep, with posterior margin tapering. Thoracic auditory spiracle exposed, small, oval.

Tegmen. Tegmina short, reaching posterior margin of pronotum, apices widely rounded. Hind wings absent.

LEGS. All femora unarmed on ventral surfaces. Fore coxa with spine; fore tibia with 5 spines on inner margin and 5 spines on outer margin of ventral surface, tibial tympana open and oval on both sides. 

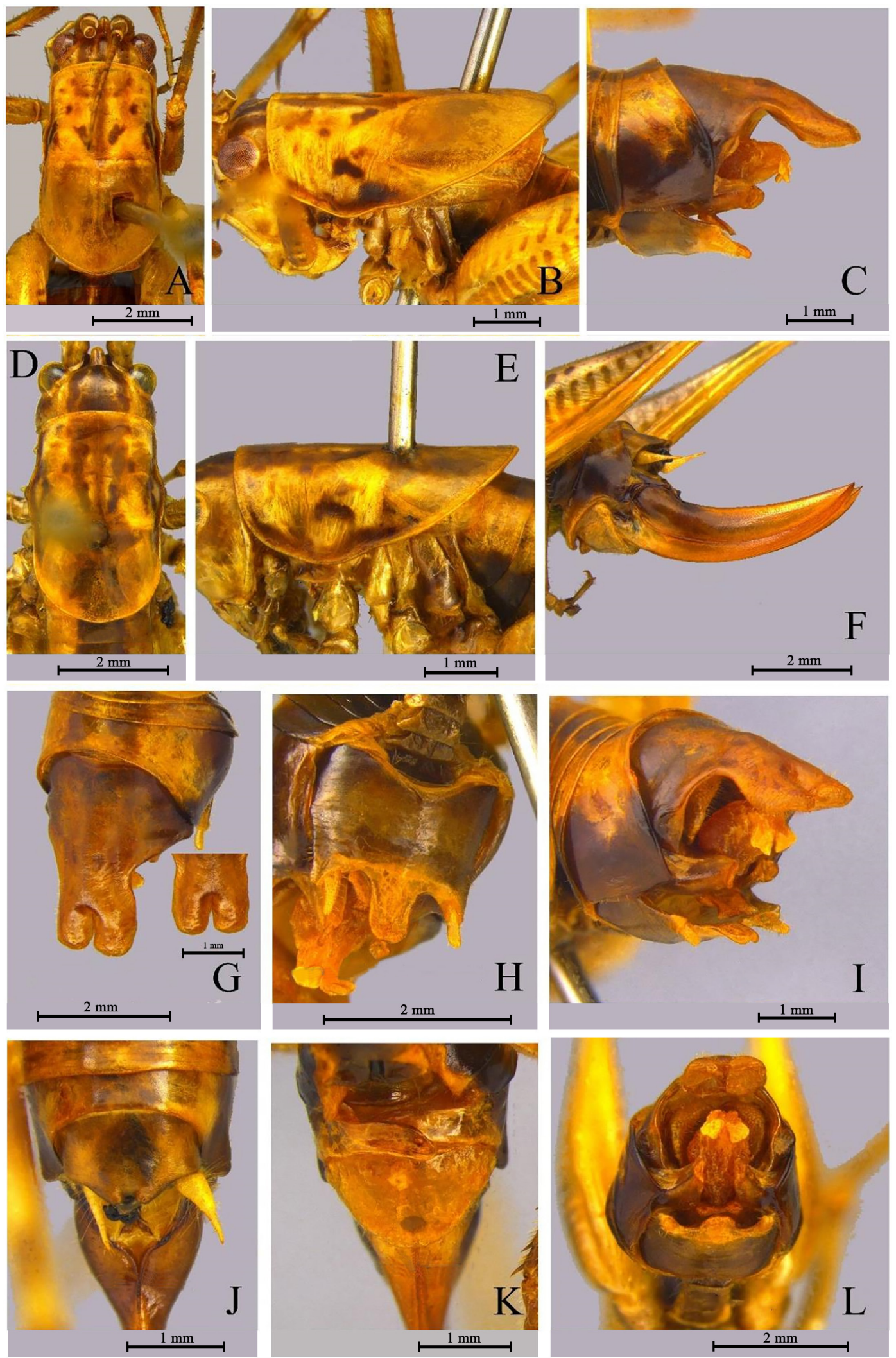

Fig. 5. Macrocosmetura truncata gen. et sp. nov. A-C, G-I, L. Holotype, $\widehat{\jmath}$ (HBU). D-F, J-K. Paratype, q (HBU). - A-B, D-E. Pronotum. A, D. Dorsal view. B, E. Lateral view. - C, F-L. Apex of abdomen. C, F. Lateral view. G, J. Dorsal view. H, K. Ventral view. I. Dorso-lateral view. L. Ventro-apical view. 
Middle tibia with 4-5 spines on each side of ventral surface. Hind tibia with 20-23 spines on each side of dorsal margin, 2 pairs of ventral apical spurs and 1 pair of dorsal apical spurs. Thoracic auditory spiracle exposed, small, elliptic.

MALE ABDOMEN. Ninth abdominal tergite expanded backwards, postero-lateral corner elongated, fingershaped, incurved, apical area curved backwards and outwards, apex rounded. Tenth abdominal tergite extended backwards, basal half broad, apical half narrow, with a median split, divided into 2 square lateral lobes. Cercus short, apical half downcurved, covered by tenth abdominal tergite, not visible in dorsal view. Genitalia sclerotized, posterior area broad, truncate (Fig. 5I). Subgenital plate with basal half broad, apical half with long middle lobe and 1 pair of short lateral lobes. Styli long inserted on inner margins of subapical areas of the lateral lobes.

Female. Pronotum shorter than male; tegmina exposed narrow edge. Ninth abdominal tergite expanded backwards and ventrad, latero-anterior corner elongated, finger-shaped, overlapped, apices rounded. Tenth abdominal tergite with posterior tapering, middle with a small notch. Cerci long conical, apices subacute. Ovipositor moderately curved upwards, base stout, terminal acute, dorsal margin denticulate, ventral margin smooth.

Coloration. Body light yellowish brown. Dorsum of head with 3 longitudinal brown stripes. Pronotum with disc light, and 1 pair of brown spots; lateral lobe with ventral edge brown. Outer surface of hind femur with some light brown spots, knee area brown, spines on all tibiae brown. Ninth to tenth abdominal tergites brown.

\section{Distribution}

China (Guizhou).

\section{Discussion}

The species diversity of the brachypterous Meconematini in China is extremely high, and the number of new taxa is still increasing (Wang T. et al. 2019a). Due to the reduced tegmina, the dispersal ability of these species is limited, indicating they occur in a restricted region. In China, thanks to the suitable climate conditions, the species of this tribe are mainly distributed in the Oriental region, with most of them being endemic (Wang T. et al. 2020c).

The new species described in this article are mainly distributed in valleys; due to geographic isolation and climate factors, the distributions of these taxa is gradually shrinking, and finally they are only distributed in valleys. As the distribution area shrinks, the dispersal ability of these taxa may decrease, consequently the body becomes smaller and tegmina degrade only for communication.

However, as the number of new species continues to grow, some problems arise, such as how to define the genera/species boundaries. Morphologically, some genera (such as Sinocyrtaspis Liu, 2000 and Paracosmetura Liu, 2000) are very similar and differ from each other by only one or two morphological characteristics (male pronotum or tenth abdominal tergite). Is this enough for distinguishing different genera? Fortunately, an integrative taxonomy could shed a bright light for those of us attempting to answer the relevant questions (such as Hemp \& Heller 2017; Hemp et al. 2018).

\section{Acknowledgments}

We are grateful for the work that peer reviewers did for this manuscript and to the collectors of specimens, as well as for the support of the Wumengshan National Nature Reserve. This project is supported by the National Natural Science Foundation of China (No. 31372232, 31672259, 31872268). 


\section{References}

Bian X., Shi F.M. \& Chang Y.L. 2012a. Review of the genus Phlugiolopsis Zeuner, 1940 (Orthoptera: Tettigoniidae: Meconematinae) from China. Zootaxa 3281 (1): 1-21.

https://doi.org/10.11646/zootaxa.3281.1.1

Bian X., Shi F.M. \& Chang Y.L. 2012b. Supplement for the genus Phlugiolopsis Zeuner, 1940 (Orthoptera: Tettigoniidae: Meconematinae) from China. Zootaxa 3411 (1): 55-62.

https://doi.org/10.11646/zootaxa.3411.1.2

Bian X., Shi F.M. \& Chang Y.L. 2013. Second supplement for the genus Phlugiolopsis Zeuner, 1940 (Orthoptera: Tettigoniidae: Meconematinae) from China, with eight new species. Zootaxa 3701 (2): 159-191. http://dx.doi.org/10.11646/zootaxa.3701.2.3

Bian X., Xie G.L., Chang Y.L. \& Shi F.M. 2014. One new genus and two new species of the tribe Meconematini (Orthoptera: Tettigoniidae: Meconematinae) from Yunnan, China. Zootaxa 3793 (2): 286-290. https://doi.org/10.11646/zootaxa.3793.2.9

Bian X., Zhu Q.D. \& Shi F.M. 2017. New genus to science of Meconematinae (Orthoptera: Tettigoniidae) from China with description of two new species and proposal of one new combination. Zootaxa 4317 (1): 165-173. https://doi.org/10.11646/zootaxa.4317.1.8

Chen L.X., Mao S.L. \& Chang Y.L. 2019. One new species of the genus Xizicus Gorochov, 1993 (Orthoptera: Tettigoniidae: Meconematinae) from Guangxi, China. Zootaxa 4652 (1): 196-200. https://doi.org/10.11646/zootaxa.4652.1.14

Cui P., Liu Y.H. \& Shi F.M. 2019. Notes on the genus Kuzicus Gorochov, 1993 (Tettigoniidae: Meconematinae: Meconematini) in China with description of one new species. Zootaxa 4651 (3): 555564. https://doi.org/10.11646/zootaxa.4651.3.8

Cui P., Liu Q. \& Shi F.M. 2020. Two new species of the genus Xizicus Gorochov, 1993 (Tettigoniidae: Meconematinae: Meconematini) from Gaoligongshan, Yunnan, China. Zootaxa 4748 (1): 44-50. https://doi.org/10.11646/zootaxa.4748.1.2

Gorochov A.V. 1993. A contribution to the knowledge of the tribe Meconematini (Orthoptera: Tettigoniidae). Zoosystematica Rossica 2 (1): 63-92.

Gorochov A.V. 1998. New and little known Meconematinae of the tribes Meconematini and Phlugidini (Orthoptera, Tettigoniidae). Zoosystematica Rossica 7 (1): 101-131.

Gorochov A.V. 2002. A new subgenus and two new species of Xizicus (Orthoptera: Tettigoniidae: Meconematinae). Zoosystematica Rossica 10 (2): 256.

Gorochov A.V. 2005. New taxa of Tettigoniidae (Orthoptera) from Vietnam. Far Eastern Entomologist 148: $1-12$.

Gorochov A.V. 2008. New and little known katydids of the tribe Meconematini (Orthoptera: Tettigoniidae: Meconematinae) from South-east Asia. Proceedings of the Zoological Institute RAS 312 (1-2): 26-42.

Gorochov A.V. 2011. Taxonomy of the katydids (Orthoptera: Tettigoniidae) from East Asia and adjacent island. Communication 3. Far Eastern Entomologist 236: 1-13.

Gorochov A.V. 2012. Taxonomy of the katydids (Orthoptera: Tettigoniidae) from East Asia and adjacent island. Communication 4. Far Eastern Entomologist 243: 1-9

Gorochov A.V. 2014. Taxonomy of the katydids (Orthoptera: Tettigoniidae) from East Asia and adjacent islands. Communication 9. Far Eastern Entomologist 283: 1-12. 
Gorochov A.V. 2015. Taxonomy of the katydids (Orthoptera: Tettigoniidae) from East Asia and adjacent islands. Communication 10. Far Eastern Entomologist 304: 1-32.

Gorochov A.V. 2019. Taxonomy of the katydids (Orthoptera: Tettigoniidae) from East Asia and adjacent islands. Communication 12. Far Eastern Entomologist 379: 1-24.

https://doi.org/10.25221/fee.379.1

Gorochov A.V., Liu C.X. \& Kang L. 2005. Studies on the tribe Meconematini (Orthoptera: Tettigoniidae: Meconematinae) from China. Oriental Insects 39 (1): 63-87.

https://doi.org/10.1080/00305316.2005.10417418

Hemp C. \& Heller K.-G. 2017. Revision of the genus Amytta (Orthoptera: Tettigoniidae, Meconematinae) and new species from East Africa. Zootaxa 4263 (2): 295-317.

Hemp C., Heller K.-G., Warchalowska-Sliwa E. \& Grzywacz B. 2018. A molecular phylogeny of East African Amytta (Orthoptera: Tettigoniidae, Meconematinae) with data on their cytogenetics. Systematic Entomology 43 (2): 239-249. https://doi.org/10.1111/syen.12269

Ingrisch S. \& Shishodia M.S. 1998. New species and records of Tettigoniidae from India (Ensifera). Mitteilungen der Schweizerischen entomologischen Gesellschaft 71: 355-372.

Ingrisch S. \& Shishodia M.S. 2000. New taxa and distribution records of Tettigoniidae from India (Orthoptera: Ensifera). Mitteilungen der Münchner Entomologischen Gesellschaft 90: 5-37.

Kano Y., Tominaga O., Tabata I., Befu T., Ishikawa H., Murai T., Mitoki T., Kawakita H., Toshima H. \& Takahashi K. 1999. Japanese brachypterous Meconematinae (Orthoptera, Tettigoniidae). Tettigonia 1 (2): $1-81$.

Liu X.W. 2000. Three new genera and seven new species of the tribe Meconematini from China (Orthoptera: Tettigonioidea: Meconematidae). Zoological Research 21 (3): 218-226.

Liu X.W. \& Zhou S. 2007. A taxonomic revision of the genus Acosmetura from China (Orthoptera, Tettigonioidea, Meconematidae). Acta Zootaxonomica Sinica 32 (1): 190-195.

Liu X.W., Zhou M. \& Bi W.X. 2008. Four new species of the genus Acosmetura from China (Orthoptera, Tettigonioidea, Meconematidae). Acta Zootaxonomica Sinica 33 (4): 761-767.

Sänger K. \& Helfert B. 1996. New Meconematinae (Ensifera: Tettigoniidae) from Thailand. European Journal of Entomology 93 (4): 607-616.

Sänger K. \& Helfert B. 2000. Notes on the Meconematinae fauna (Ensifera, Tettigoniidae) of Thailand. Senckenbergiana Biologica 80: 141-147.

Sänger K. \& Helfert B. 2004. Four new species and new records of Meconematinae in Thailand (Insecta, Ensifera, Tettigoniidae). Senckenbergiana Biologica 84 (1-2): 45-58.

Shi F.M. \& Bian X. 2012. A revision of the genus Pseudocosmetura (Orthoptera: Tettigoniidae: Meconematinae). Zootaxa 3545 (1): 76-82. https://doi.org/10.11646/zootaxa.3545.1.5

Shi F.M. \& Bian X. 2013. One new genus and species of the tribe Meconematini (Orthoptera, Tettigoniidae) from Sichuan, China with description of the male sex and transfer of Acosmetura carinata Liu, Zhou \& Bi, 2008 to the new genus. Zootaxa 3599 (4): 390-394. https://doi.org/10.11646/zootaxa.3599.4.7

Shi F.M. \& Zheng Z.M. 1994. Two new species of katydids from Sichuan (Orthoptera: Tettigonioidea). Journal of Shaanxi Normal University (Natural Science Edition) 8 (1): 44-46.

Shi F.M., Bian X. \& Chang Y.L. 2013. A new genus and two new species of the tribe Meconematini (Orthoptera: Tettigoniidae) from China. Zootaxa 3681 (2): 163-168.

https://doi.org/10.11646/zootaxa.3681.2.5 
Tan M.K. \& Wahab R.B.H.A. 2018. New taxa and notes of katydids from the tribe Meconematini (Orthoptera: Meconematinae) from Brunei Darussalam (Part 2). Zootaxa 4407 (4): 582-590.

https://doi.org/10.11646/zootaxa.4407.4.10

Tan M.K., Gorochov A.V. \& Wahab R.B.H.A. 2017. New taxa and notes of katydids from the tribe Meconematini (Orthoptera: Meconematinae) from Brunei Darussalam. Zootaxa 4337 (3): 390-402. https://doi.org/10.11646/zootaxa.4337.3.4

Wang H.J., Cao C.Q. \& Shi F.M. 2013. One new species and one new combination of the genus Neocyrtopsis Liu \& Zhang, 2007 (Orthoptera: Meconematinae) from Emeishan, China. Zootaxa 3681 (2): 182-186. https://doi.org/10.11646/zootaxa.3681.2.8

Wang H.Q., Liu X.W., Li K. \& Fang Y. 2012. A new genus and five new species of the Meconematini (Orthoptera: Tettigoniidae: Meconematinae). Zootaxa 3521 (1): 51-58.

https://doi.org/10.11646/zootaxa.3521.1.3

Wang H.Q., Liu X.W. \& Li K. 2013. Revision of the genus Neocyrtopsis Liu \& Zhang (Orthoptera: Tettigoniidae: Meconematinae). Zootaxa 3626 (2): 279-287. https://doi.org/10.11646/zootaxa.3626.2.5

Wang H.Q., Liu X.W. \& Li K. 2014. A synoptic review of the genus Thaumaspis Bolívar (Orthoptera, Tettigoniidae, Meconematinae) with the description of a new genus and four new species. ZooKeys 443: 11-33. https://doi.org/10.3897/zookeys.443.7529

Wang H.Q., Liu X.W. \& Li K. 2015a. New taxa of Meconematini (Orthoptera: Tettigoniidae: Meconematinae) from Guangxi, China. Zootaxa 3941 (4): 509-541.

https://doi.org/10.11646/zootaxa.3941.4.3

Wang H.Q., Qin Y.Y., Liu X.W. \& Li K. 2015b. Review of the genus Cyrtopsis Bey-Bienko with a new species, a new combination and some new descriptions. Zootaxa 4057 (3): 353-370.

https://doi.org/10.11646/zootaxa.4057.3.3

Wang P., Bian X. \& Shi F.M. 2016. One new species of the genus Acosmetura (Tettigoniidae: Meconematinae) from Hubei, China. Zootaxa 4171 (2): 389-394.

http://doi.org/10.11646/zootaxa.4171.2.12

Wang T., Chen P.W. \& Shi F.M. 2019a. Two new species of the tribe Meconematini (Orthoptera: Tettigoniidae: Meconematinae) from Taiwan. Zootaxa 4564 (1): 295-300.

https://doi.org/10.11646/zootaxa.4564.1.13

Wang T., Shi F.M. \& Chang Y.L. 2019b. Revision of the genus Sinocyrtaspis Liu, 2000 (Orthoptera: Tettigoniidae: Meconematinae). Zootaxa 4609 (1): 127-138. https://doi.org/10.11646/zootaxa.4609.1.5

Wang T., Huang J.H. \& Shi F.M. 2020a. One new genus and species of the tribe Meconematini (Orthoptera: Tettigoniidae: Meconematinae) from China. Zootaxa 4750 (1): 138-142.

https://doi.org/10.11646/zootaxa.4750.1.8

Wang T., Xin Y.R. \& Shi F.M. 2020b. New interpretations of the genus Sinocyrtaspis Liu, 2000 (Orthoptera: Tettigoniidae: Meconematinae) from China. Zootaxa 4718 (4): 584-590.

https://doi.org/10.11646/zootaxa.4718.4.11

Wang T., Zhu Q.D, Heller K.-G., Zhou Z.J. \& Shi F.M. 2020c. Phylogenetic relationships and phylogeography of the genus Sinocyrtaspis Liu, 2000 (Orthoptera: Tettigoniidae: Meconematinae) reveal speciation processes related to climate change. Systematic Entomology 45 (1): 144-159.

https://doi.org/10.1111/syen.12384

Xia K.L. \& Liu X.W. 1992. Orthoptera: Tettigonioidea and Grylloidea. In: Huang F.S. (ed.) Insects of Wuling Mountains Area, Southwestern China: 87-113. Science Press, Beijing. 
Manuscript received: 12 February 2021

Manuscript accepted: 3 March 2021

Published on: 8 June 2021

Topic editor: Nesrine Akkari

Desk editor: Radka Rosenbaumová

Printed versions of all papers are also deposited in the libraries of the institutes that are members of the EJT consortium: Muséum national d'histoire naturelle, Paris, France; Meise Botanic Garden, Belgium; Royal Museum for Central Africa, Tervuren, Belgium; Royal Belgian Institute of Natural Sciences, Brussels, Belgium; Natural History Museum of Denmark, Copenhagen, Denmark; Naturalis Biodiversity Center, Leiden, the Netherlands; Museo Nacional de Ciencias Naturales-CSIC, Madrid, Spain; Real Jardín Botánico de Madrid CSIC, Spain; Zoological Research Museum Alexander Koenig, Bonn, Germany; National Museum, Prague, Czech Republic. 